\title{
Comparative clinico-haematological analysis in young Zebu cattle experimentally infected with Trypanosoma vivax isolates from tsetse infested and non-tsetse infested areas of Northwest Ethiopia
}

\author{
Shimelis Dagnachew ${ }^{1,4,5^{*}}$, Melkamu Bezie ${ }^{1}$, Getachew Terefe ${ }^{1}$, Getachew Abebe ${ }^{2}$, J. David Barry ${ }^{3}$ \\ and Bruno M. Goddeeris ${ }^{4}$
}

\begin{abstract}
Background: Ethiopia, particularly in the Northwest region, is affected by both tsetse and non-tsetse fly transmitted trypanosomosis, with significant impact on livestock productivity. The aim of this study was to determine and compare clinical findings and haematological values between experimental infections induced by Trypanosoma vivax isolates from areas of either transmission mode. Sixteen young (aged between 6 and 12 months) Zebu cattle (Bos indicus), purchased from a trypanosome-free area and confirmed to be trypanosome-negative, were randomly assigned into four groups of four animals. Groups 1,2 and 3 were infected with an isolate from a tsetse infested or one of two isolates from a non-tsetse infested area, and group 4 was a non-infected control. All animals in the infected groups were inoculated intravenously with $2 \times 10^{6}$ trypanosomes from donor animals. The experimental animals were monitored for eight consecutive weeks post infection for clinical signs, parasitaemia and haematological changes in packed cell volume (PCV), haemoglobin concentration (Hgb), total red blood cell (RBC) and white blood cell (WBC) counts, differential WBC count and blood indices (mean corpuscular volume [MCV], mean corpuscular haemoglobin and mean corpuscular haemoglobin concentration).
\end{abstract}

Results: Infection was characterized by reduced feed intake, weakness, pyrexia, parasitaemia, rough hair coat, enlarged prescapular lymph nodes, lacrimation, weight loss, pallor mucus membrane and dehydration. Body weight loss in all infected groups was significantly higher than in the non-infected control. Similarly, body weight loss was higher $(P<0.001)$ in animals infected with the tsetse infested isolate than with the non-tsetse infested isolates. The mean PCV, Hgb, total RBC and WBC counts were lower $(P<0.001)$, and mean MCV was higher $(P=0.01)$ in all infected groups than in non-infected control animals at different time points during the study period. Except for minor variations in haematological values, the overall changes were similar in all infected groups.

Conclusion: Clinical signs and significant reduction in haematological values in the infected groups indicated the pathogenicity of the T. vivax parasites. Pathogenicity of T. vivax from the non-tsetse infested area can be considered as nearly as important as that of its counterpart derived from the tsetse infested area.

Keywords: Clinical findings, Haematological analysis, Northwest Ethiopia, Trypanosoma vivax, Zebu cattle

\footnotetext{
* Correspondence: dagne2121@gmail.com

1 Department of Pathology and Parasitology, College of Veterinary Medicine and Agriculture of Addis Ababa University, P.O. Box: 34, Debre Zeit, Ethiopia ${ }^{4}$ Department of Biosystems, Faculty of Bioscience Engineering, Catholic

University of Leuven, 30 bus 2456, B-3001 Heverlee, Belgium

${ }^{5}$ Faculty of Veterinary Medicine, University of Gondar, P.O. Box: 196, Gondar,

Ethiopia

Full list of author information is available at the end of the article
}

C Biomed Central

(C) 2015 Dagnachew et al.; licensee BioMed Central. This is an Open Access article distributed under the terms of the Creative Commons Attribution License (http://creativecommons.org/licenses/by/4.0), which permits unrestricted use, distribution, and reproduction in any medium, provided the original work is properly credited. The Creative Commons Public Domain Dedication waiver (http://creativecommons.org/publicdomain/zero/1.0/) applies to the data made available in this article unless otherwise stated. 


\section{Introduction}

Trypanosomosis is a parasitic disease caused by different species of flagellated protozoa belonging to the genus Trypanosoma which inhabit the blood, various body tissues and fluids of vertebrate hosts. However, the extent of tissue invasion varies among the different species of the parasite $[1,2]$. The disease is frequently fatal and is a serious constraint to agricultural production in large parts of sub-Saharan Africa, exhibiting direct impacts on livestock productivity, livestock management and human settlement, and indirect impacts on crop agriculture and human welfare [3]. Trypanosomosis is transmitted cyclically by tsetse flies; however, some species of trypanosome such as $T$. vivax are also transmitted mechanically, by other biting flies, such as several tabanids [4]. T. vivax presents a short and simple life cycle in contrast with $T$. brucei and, to a lesser extent, with $T$. congolense [5]. This simpler life cycle is thought to have enabled $T$. vivax to adapt to different vectors and hosts, possibly explaining why it has emerged rapidly in South America and non-tsetse infested regions of Africa [6, 7]. In Ethiopia, trypanosomosis is mainly prevalent in the northwest and southwest areas of the country [8-11], where $T$. vivax and $T$. congolense have been identified as the prevalent species. T. vivax is distributed in both tsetse infested and non-tsetse infested areas, while T. congolense is restricted to tsetse infested areas. Both species of trypanosome affect a large number of domestic animals, and mainly cattle, which are integral to crop production in Ethiopia. As opposed to prevalence, the comparative pathological impact of $T$. vivax parasites which is transmitted cyclically by tsetse fly and mechanically by other biting flies is not well known.

The pre-patent period of bovine trypanosomosis is usually 1 to 3 weeks, depending on the virulence of the infecting trypanosome, the infective dose and the immune status of the host. Symptoms associated with trypanosomosis include pallor of the mucous membranes, enlargement of lymph nodes and spleen, weakness, loss of condition, abortion and reduced milk production [12]. The evaluation of haematological values is of paramount importance in determining the health status of animals [13]. The main haematological changes observed in natural cases of bovine trypanosomosis are anaemia associated with decrease in packed cell volume (PCV), haemoglobin $(\mathrm{Hgb})$ and total red blood cell (RBC) counts, and severe leukopenia $[14,15]$. The severity of anaemia which occurs in infection can be related to differences in virulence among trypanosome strains and species, and factors associated with the host like age, breed, and nutritional status of infected animals [14].

Isolates of T. vivax from different parts of the world have been shown to differ in pathogenicity and infectivity for laboratory rodents and in requirements for cultivation in vitro [7]. However, despite the severe disease it causes, $T$. vivax remains largely unstudied in both tsetse and non-tsetse infested areas. Moreover, less is known about the biology of $T$. vivax than about that of T. brucei and T. congolense in East Africa. It is generally believed that East African strains of T. vivax are less pathogenic and cause a chronic form of infection; however, occasional outbreaks of $T$. vivax acute infection have been reported in Kenya and Uganda [16]. For $T$. vivax, neither the possible occurrence of such an acute disease form, nor pathogenic impact at large, has been investigated in Ethiopia. Furthermore, information on the impact of $T$. vivax infections on haematological values is scarce. To attain better understanding of the pathogenicity of T. vivax in northwest Ethiopia, the present study determined and compared clinical findings and haematological values induced by three $T$. vivax isolates, one from tsetse infested area and two from nontsetse infested area in experimentally infected young Zebu cattle.

\section{Materials and methods \\ Experimental study site}

The study was conducted, from March to May 2014, in a fly proof animal facility recently established by GALVmed at the premises of the College of Veterinary Medicine and Agriculture of Addis Ababa University. The area is located about $45 \mathrm{~km}$ Southeast of Addis Ababa at $9^{\circ} \mathrm{N}$ latitude and $40^{\circ} \mathrm{E}$ longitude and altitude $1850 \mathrm{~m}$ above sea level.

\section{Experimental animals}

Sixteen young Zebu (Bos indicus) cattle (six male, ten female) aged between 9 and 12 months were purchased from Debre Berehan, which is located in a trypanosome free area of northcentral highland Ethiopia. Before transportation, animals were treated with long acting oxytetracycline (Alamycin LA, Norbrook, Ireland). On arrival at the experimental study site, the animals were ear-tagged and screened for haemoparasites and other internal and external parasites. Animals were dewormed with albendazole (Albenda-QK, Chengdu Qiankun, China) and ivermectin (Ivermectin $1 \%$, Chengdu Qiankun, China), to control internal and external parasites. Prior to the experiment, the animals were acclimatized for one month to the new environment, handling and feeding conditions.

\section{Feeding and animal management}

Throughout the experimental period, animals were fed ad libitum with grass hay and water, with supplements of concentrates and mineral licks. All protocols and procedures of the handling of animals were according to the international guiding principles for biomedical research proposed by the Council for International Organizations 
of Medical Sciences [17] and ARRIVE guidelines [18]. The research was authorized by the Animal Research and Ethics Review Committee of the College of Veterinary Medicine and Agriculture of Addis Ababa University (Permit No: VM/ERC/003/04/013). At the end of the experiment, all of the infected animals were euthanized by jugular vein injection of an overdose of sodium phenobarbitol. In addition, any animals with the severe clinical manifestations of recumbence and PCV below $15 \%$ were euthanized using the above procedure.

\section{Experimental groups}

The experimental animals were divided randomly into four equal groups of four animals per group. Group 1 (TT) were infected with T. vivax isolated from a tsetse infested area; Group 2 (NT1) with T. vivax isolated from a non-tsetse infested area; Group 3 (NT2) with another strain of $T$. vivax isolated from a non-tsetse infested area; and Group 4 (NIC) was the non-infected control. Each group was kept in a separate pen. Attempts to induce infections with a second strain isolated from a tsetse infested area were unsuccessful, restricting the experiment to only one strain of this type.

\section{Trypanosome challenge}

The $T$. vivax parasites were originally isolated from naturally infected cattle from the Jabitehenan district of Birsheleko area (ETBS2-Ethiopia Birsheleko isolate 2-tsetse infested area) and Bahir Dar Zuria district (ETBD2 and ETBD3-Ethiopia Bahir Dar isolate 2 and 3-non-tsetse infested area). From these animals, stabilates were prepared and cryopreserved in liquid nitrogen $\left(-196{ }^{\circ} \mathrm{C}\right)$. The isolates were confirmed as pure T. vivax by polymerase chain reaction [19] and microsatellite analysis [20]. The cryopreserved stabilates were propagated in three healthy donor calves. The donor animals were examined daily for parasitaemia using the rapid "matching" method [21]. All experimental animals except the noninfected controls received intravenously $2 \mathrm{~mL}$ of blood taken from donor animals at a parasitaemia level of $10^{6}$ trypanosomes $/ \mathrm{mL}$.

\section{Clinical and parasitological examinations}

Animals were examined daily for clinical parameters at their pen throughout the study period. Rectal temperature was taken twice weekly, in the morning, using a digital thermometer. Body weight of each animal was measured weekly on an electronic cattle weighing scale (TAL-TEC, South Africa). Body weight gain was calculated weekly, relative to the day 0 body weight. Blood samples were examined for the presence of trypanosomes daily until the detection of parasites, then weekly, using the standard parasitological methods of wet blood smear microscopy and the buffy coat technique [22]. All the sampling protocols was designed according to ARRIVE guidelines that minimize influence on the results of the research.

\section{Haematological analysis}

About $5 \mathrm{~mL}$ of blood was collected weekly during the study period from the jugular vein of all experimental animals using ethylene diamine tetra acetic acid (EDTA) coated vacutainer tubes. Haematological parameters measured included: PCV, Hgb concentration, RBC count, erythrocyte indices (mean corpuscular volume $(\mathrm{MCV})$, mean corpuscular haemoglobin $(\mathrm{MCH})$ and mean corpuscular haemoglobin concentration $(\mathrm{MCHC})$ ), and total and differential white blood cell (WBC) count. $\mathrm{PCV}$ was measured by the haematocrit centrifugation technique using a Hawksley microhaematocrit reader. Total RBC and WBC counts were carried out manually using the improved Haemocytometer. Hgb concentration was measured by the Sahili's Acid-Haematin method. Erythrocyte indices were also calculated from the above haematological values using the following formulas.

$$
\begin{aligned}
& \mathrm{MCV}=\operatorname{PCV}(\%) \times 10 / \mathrm{RBC} \text { count } \\
& \mathrm{MCHC}=\mathrm{Hgb} \text { con } . \times 100 / \mathrm{PCV} \\
& \mathrm{MCH}=\mathrm{Hgb} \text { con } \times 10 / \mathrm{RBC} \text { count }
\end{aligned}
$$

Thin blood smears were stained with Giemsa's for differential WBC counts, which were based on 100 cells per slide according to their staining reactions; shape of the nucleus, and presence or absence of granules in their cytoplasm [13]. The absolute numbers of leukocytes, eosinophils, lymphocytes, neutrophils, basophils and monocytes per milliliter of blood were obtained by using the differential white cell count percentages and the total leukocytes count.

\section{Data analysis}

All data were entered into an Excel spread sheet and imported into SPSS version 20 statistical software. Descriptive statistics were used to describe the data. Differences in haematological variables, rectal body temperature and body weight loss measured between groups were assessed by a one-way ANOVA. The significant level was set at $(P<0.05)$.

\section{Results}

\section{Clinical findings and appearance of parasitaemia}

All the infected cattle developed clinical trypanosomosis, which was characterized by a variety of clinical signs. Reduced feed intake, weakness, fever, rough hair coat, enlarged superficial lymph nodes, congested mucus membranes, lacrimation and weight loss were early clinical findings, whereas pallor of mucus membranes, dehydration, and emaciation were predominant 
later in infection. The major clinical signs (reduced feed intake, enlarged lymph nodes, rough hair coat and pallor of mucus membranes) observed at each time point were added together and scored accordingly to the experimental groups, as indicated in Fig. 1a. Signs observed less frequently included dullness, diarrhoea, corneal opacity and recumbence. Two animals (one from the TT and the other from the NT1 group) showed severe clinical signs of recumbence and PCV below $15 \%$ and hence were euthanized on post infection day (PID) 30. The mean rectal temperatures of infected groups $\left(39.1{ }^{\circ} \mathrm{C} \pm 0.64,39.2{ }^{\circ} \mathrm{C} \pm 0.70,39.2{ }^{\circ} \mathrm{C} \pm 0.70\right.$ for TT, NT1, NT2, respectively) were significantly higher $(P<0.001)$ than for the control group $\left(38.39{ }^{\circ} \mathrm{C} \pm 0.30\right)$. However, no significant difference was found among infected groups. The temperature of infected animals started rising from the PID 4, coincident with the appearance of parasitaemia, and then fluctuated throughout the study period (Fig. 1b). The highest mean temperature recorded was $40.15{ }^{\circ} \mathrm{C}$, from the NT1 group on PID 7. Infected groups significantly lost body weight, while the control group steadily gained weight $(P<0.001)$. Body weight loss was significantly higher $(P$ $<0.001)$ in group TT than in groups NT1 and NT2. This decrease in body weight of infected animals was marked and progressive between PIDs 0 and 28. Thereafter, weight tended to stabilize, but remained significantly $(P<0.001)$ below that of control animals until the termination of the experiment (Fig. 1c).

Parasitaemia was detected by PID 4 in animals infected with $T$. vivax isolates from the non-tsetse infested area and by PID 7 in animals infected with the tsetse infested isolate. Animals in group NT2 showed early peak parasitaemia on PID 7, as opposed to the TT and NT1 groups, which showed peak parasitaemia on PID 14. Animals remained trypanosome positive with fluctuating parasitaemia throughout the experimental period. High fluctuations were seen in animals infected with non-tsetse isolates, while parasitaemia dropped uniformly after its initial peak for the tsetse infested isolate infected group (Fig. 1d). In group NT2, despite sharp decline after the initial peak on PID 7, the parasitaemia persisted, reaching its highest level from PID 35 to 56.

\section{Haematological findings}

The overall mean haematological changes of all experimental animals during the study period are summarized in Tables 1 and 2. Likewise, the haematological changes of all experimental animals at different time points of the study period are indicated in Fig. $2 a-d$. Significant decrease $(P<0.05)$ of mean PCV, Hgb concentration, total RBC and WBC counts was detected in all infected groups compared with the non-infected control group. Mean PCV values of the infected groups decreased gradually, attaining significant reduction by PID 14 (Fig. 2a). All infected groups showed significant decrease $(P<0.001)$ in mean PCV as compared with the noninfected control group. In addition, $\mathrm{PCV}$ values of group NT2 were significantly lower $(P=0.001)$ than those of group TT. Infected groups had significant reduction $(P<0.001)$ in mean $\mathrm{Hgb}$ concentration as compared with the non-infected control group (Fig. 2b). Moreover, the mean $\mathrm{Hgb}$ concentration value of group NT2 was significantly lower $(P=0.030)$ than that of group TT. Reductions in Hgb concentration for groups TT and NT1 started to reach significance at PID 14, but did so in group NT2 only by PID 21 and persisted until the end of the study. For group NT1, Hgb concentration was not significantly reduced $(P=0.062)$ on PID 42 .

All of infected groups had a significantly lower $(P<0.001)$ mean total RBC count as compared with the control group (Fig. 2c). Total RBC counts of groups NT1 and NT2 were also significantly lower $(P=0.007$, and $P<0.001$, respectively) than those of group TT. Reductions in mean total RBC count became significant at PID 14 for groups NT1 and NT2, but at PID 21 for group TT, in which the low level persisted until PID 42. However, the reduction was not significant on PID 49 and 56 for groups TT and NT1, respectively. There was a significant increase in mean $\mathrm{MCV}$ $(P=0.001)$ in infected groups compared with that of the non-infected group. No significant difference was observed in mean $\mathrm{MCH}$ and $\mathrm{MCHC}$ values $(P=0.056$ and 0.581 , respectively) between infected and non-infected groups.

The mean total WBC count of infected groups was significantly lower $(P<0.001)$ compared with the noninfected control (Fig. 2d). However, there was no significant difference in mean WBC count between infected groups. The mean differential WBC count (Table 2) indicated that lymphocyte, neutrophil and eosinophil levels were depressed in infected groups $(P<0.001)$. Monocyte count showed insignificant elevation. Mean leukocyte counts in the infected groups began to decline between PID 14 and 21 and remained below the level of the noninfected group until PID 49 and 56 for NT and TT groups, respectively. The basophils counts in all the three infected groups fluctuated within the control levels throughout the experiment.

\section{Discussion}

\section{Clinical findings and development of parasitaemia}

The onset of clinical manifestations coincided with the beginning of parasitaemia and these parameters progressed together. Similar findings were reported by Adeiza et al. [23] in Savannah brown goats experimentally infected with $T$. brucei and T. vivax. The more pronounced loss in body weight gain of the group infected with $T$. vivax from tsetse area might be due to the more severe dehydration and anorexia manifested. Furthermore, 

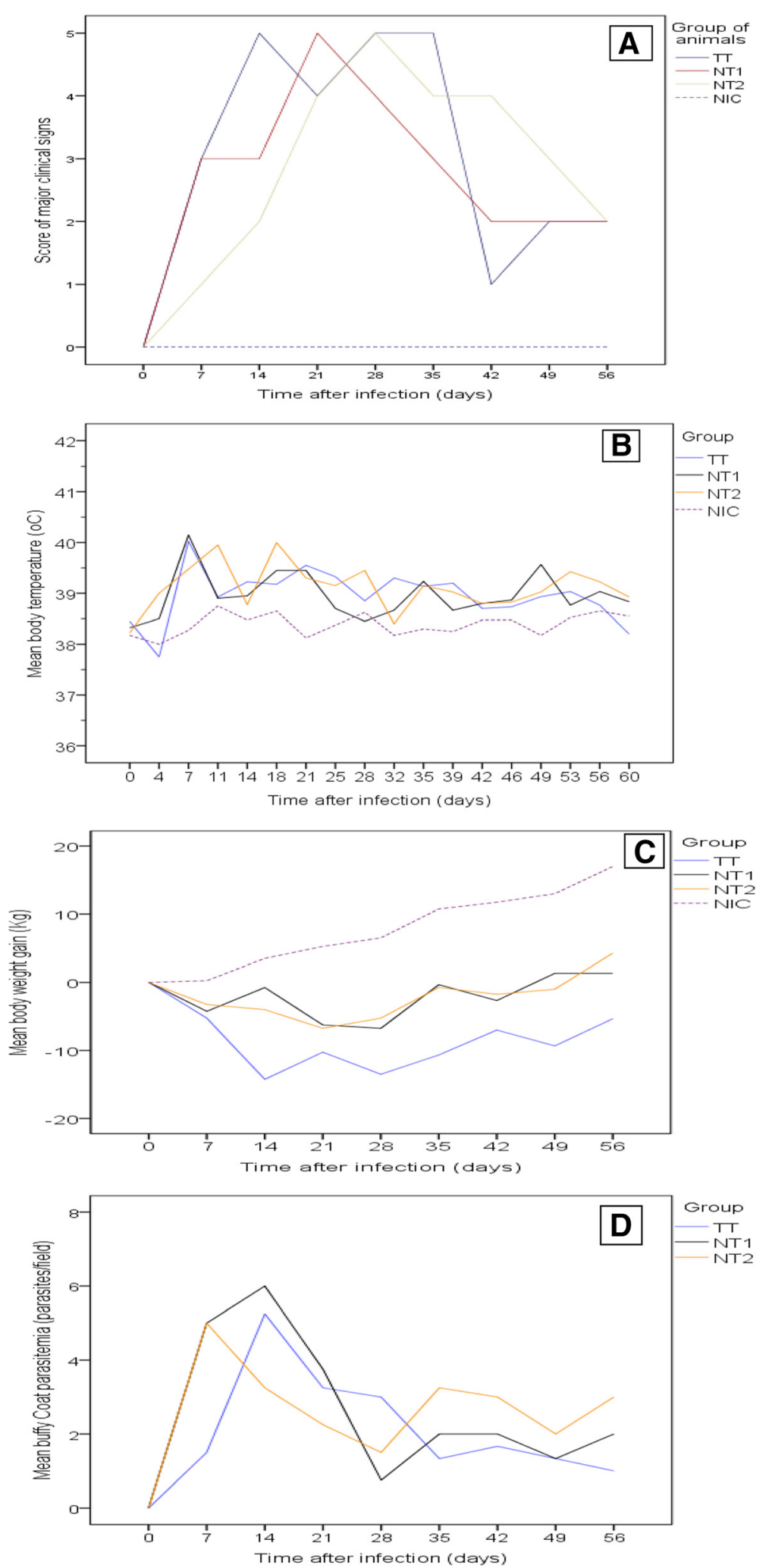

Fig. 1 Clinical findings and appearance of parasitaemia in young zebu cattle experimentally infected with $T$. vivax isolates from tsetse-infested (TT) and non-tsetse infested (NT1 and NT2) areas and non-infected control (NIC) groups during the study period. a Score of major clinical signs (reduction in feed intake, enlarged lymph nodes, rough hair coat and pallor of mucus membranes), (b) Mean rectal temperature in ${ }^{\circ} \mathrm{C}$, (c) Mean body weight gain in $\mathrm{kg}$, (d) Mean waves of parasitaemia (score per microscopic field) 
Table 1 Mean haematological values during the study period (mean of recordings of 8 consecutive weeks) in young Zebu cattle experimentally infected with $T$. vivax isolates from tsetse infested (TT) and non-tsetse infested (NT1 and NT2) areas, and non-infected control (NIC)

\begin{tabular}{|c|c|c|c|}
\hline Hematological values & Group & Mean $\pm S D$ & $95 \%$ Cl for mean \\
\hline \multirow[t]{4}{*}{ PCV values (\%) } & $\pi$ & $22.72 \pm 3.55^{a}$ & $21.44-24.0$ \\
\hline & NT1 & $20.41 \pm 3.67^{\mathrm{ab}}$ & $19.08-21.73$ \\
\hline & NT2 & $19.39 \pm 4.59^{b}$ & $17.84-20.94$ \\
\hline & $\mathrm{NIC}$ & $27.19 \pm 2.05^{c}$ & $26.5-27.89$ \\
\hline \multirow[t]{4}{*}{ Hgb concentration (g/dl) } & $\pi$ & $7.73 \pm 1.13^{\mathrm{a}}$ & $7.22-8.25$ \\
\hline & NT1 & $6.82 \pm 1.34^{\mathrm{ab}}$ & $6.34-7.30$ \\
\hline & NT2 & $6.53 \pm 1.86 a^{b}$ & $5.90-7.17$ \\
\hline & NIC & $9.17 \pm 0.68^{c}$ & $8.94-9.40$ \\
\hline \multirow[t]{4}{*}{ RBC count $\left(\times 10^{6} / \mu \mathrm{l}\right)$} & $\pi$ & $5.75 \pm 0.91^{\mathrm{a}}$ & $5.42-6.08$ \\
\hline & NT1 & $4.85 \pm 1.20^{\mathrm{ab}}$ & $4.41-5.28$ \\
\hline & NT2 & $4.54 \pm 1.46^{\mathrm{b}}$ & $4.05-5.04$ \\
\hline & $\mathrm{NIC}$ & $6.47 \pm 0.64^{c}$ & $6.25-6.68$ \\
\hline \multirow[t]{4}{*}{$\mathrm{MCV}(\mathrm{fl})$} & $\pi$ & $42.29 \pm 3.77^{\mathrm{a}}$ & $41.02-43.57$ \\
\hline & NT1 & $43.25 \pm 7.08^{\mathrm{a}}$ & $40.70-45.80$ \\
\hline & NT2 & $44.34 \pm 7.83^{\mathrm{a}}$ & $41.69-47.00$ \\
\hline & NIC & $39.64 \pm 2.98^{b}$ & $38.57-40.72$ \\
\hline \multirow[t]{4}{*}{$\mathrm{MCH}(\mathrm{pg})$} & $\pi$ & $13.46 \pm 1.34^{\mathrm{a}}$ & $12.98-13.95$ \\
\hline & NT1 & $14.40 \pm 2.23^{a}$ & $13.60-15.21$ \\
\hline & NT2 & $14.72 \pm 2.36^{a}$ & $13.92-15.52$ \\
\hline & $\mathrm{NIC}$ & $14.25 \pm 1.24^{\mathrm{a}}$ & $13.83-14.68$ \\
\hline \multirow[t]{4}{*}{$\mathrm{MCHC}(\mathrm{g} / \mathrm{dl})$} & $\pi$ & $33.97 \pm 2.36^{\mathrm{a}}$ & $33.12-34.82$ \\
\hline & NT1 & $33.38 \pm 1.61^{a}$ & $32.80-33.96$ \\
\hline & NT2 & $33.39 \pm 2.56^{a}$ & $32.52-34.26$ \\
\hline & $\mathrm{NIC}$ & $33.74 \pm 1.34^{\mathrm{a}}$ & $33.28-34.19$ \\
\hline \multirow[t]{4}{*}{ WBC count $\left(\times 10^{3} / \mu l\right)$} & $\Pi$ & $6.78 \pm 2.51^{\mathrm{a}}$ & $5.87-7.68$ \\
\hline & NT1 & $7.04 \pm 2.03^{a}$ & $6.31-7.77$ \\
\hline & NT2 & $6.75 \pm 1.57^{\mathrm{a}}$ & $6.21-7.28$ \\
\hline & $\mathrm{NIC}$ & $9.03 \pm 1.17^{b}$ & $8.64-9.43$ \\
\hline
\end{tabular}

In each parameter of variables, superscripts with different letters indicate significant difference between values at $P<0.01$

loss of body weight during trypanosome infections in domestic animals has been reported frequently reported by several authors [24, 25], indicating the economic impact of the disease.

The earlier appearance of parasitaemia with the nontsetse isolates might be associated with the fact that artificial intravenous inoculation is more similar to mechanical transmission of $T$. vivax than to cyclical transmission of tsetse adapted T. vivax. Another explanation for the early onset of parasitaemia in the NT infected cattle might be a higher growth rate of the NT parasite. This possibility is supported by the phenomenon in T. brucei [26] and Plasmodium chabaudi [27] of marked increase in parasitaemia
Table 2 Mean differential WBC counts during the study period (mean of recordings of 8 consecutive weeks) in young Zebu cattle experimentally infected with $T$. vivax isolates from tsetse infested (TT) and non-tsetse infested (NT1 and NT2) areas, and non-infected control (NIC)

\begin{tabular}{|c|c|c|c|}
\hline Haematological values & Group & Mean \pm SD & $95 \%$ Cl for mean \\
\hline \multirow[t]{4}{*}{ Lymphocyte count $\left(\times 10^{3} / \mu \mathrm{l}\right)$} & $\pi$ & $4.11 \pm 1.82^{\mathrm{a}}$ & $3.46-4.77$ \\
\hline & NT1 & $4.11 \pm 1.07^{\mathrm{a}}$ & $3.72-4.50$ \\
\hline & NT2 & $4.68 \pm 1.44^{\mathrm{a}}$ & 4.19-5.16 \\
\hline & $\mathrm{NIC}$ & $5.54 \pm 0.79^{b}$ & $5.28-5.81$ \\
\hline \multirow[t]{4}{*}{ Monocyte count $\left(\times 10^{3} / \mu \mathrm{l}\right)$} & $\pi$ & $0.59 \pm 0.35^{\mathrm{a}}$ & $0.46-0.71$ \\
\hline & NT1 & $0.57 \pm 0.28^{\mathrm{a}}$ & $0.47-0.68$ \\
\hline & NT2 & $0.42 \pm 0.20^{\mathrm{a}}$ & $0.35-0.49$ \\
\hline & $\mathrm{NIC}$ & $0.49 \pm 0.20^{\mathrm{a}}$ & $0.42-0.56$ \\
\hline \multirow[t]{4}{*}{ Neutrophil count $\left(\times 10^{3} / \mu \mathrm{l}\right)$} & $\pi$ & $1.84 \pm 1.00^{\mathrm{a}}$ & $1.48-2.20$ \\
\hline & NT1 & $2.14 \pm 1.44^{\mathrm{a}}$ & $1.62-2.67$ \\
\hline & NT2 & $1.50 \pm 0.75^{\mathrm{a}}$ & $1.24-1.75$ \\
\hline & $\mathrm{NIC}$ & $2.60 \pm 0.77^{b}$ & $2.34-2.86$ \\
\hline \multirow[t]{4}{*}{ Eosinophil count $\left(\times 10^{3} / \mu l\right)$} & $\pi$ & $0.20 \pm 0.22^{\mathrm{a}}$ & $0.11-0.28$ \\
\hline & NT1 & $0.18 \pm 0.11^{\mathrm{a}}$ & $0.15-0.23$ \\
\hline & NT2 & $0.13 \pm 0.14^{\mathrm{a}}$ & $0.08-0.18$ \\
\hline & $\mathrm{NIC}$ & $0.40 \pm 0.23^{b}$ & $0.32-0.48$ \\
\hline \multirow[t]{4}{*}{ Basophil count $\left(\times 10^{3} / \mu l\right)$} & $\pi$ & $0.04 \pm 0.05^{\mathrm{a}}$ & $0.02-0.06$ \\
\hline & NT1 & $0.02 \pm 0.04^{\mathrm{a}}$ & $0.00-0.04$ \\
\hline & NT2 & $0.01 \pm 0.03^{\mathrm{a}}$ & $0.00-0.03$ \\
\hline & $\mathrm{NIC}$ & $0.02 \pm 0.04^{\mathrm{a}}$ & $0.01-0.03$ \\
\hline
\end{tabular}

In each parameter of variables, superscripts with different letters indicate significant difference between values at $P<0.05$

and virulence when these parasites are syringe passaged in rodents. These alterations have been attributed to a lack of a reset mechanism when going through the vector and it seems possible that loss of pleomorphism might apply to mechanically transmitted lines in T. viax $[28,29]$. Similarly, we have reported previously that non-tsetse transmitted $T$. vivax displayed earlier parasitaemia than did a tsetse transmitted isolate in experimental infection of cattle [30]. In the current work, although parasites appeared in the blood faster in the NT groups, virulence did not seem to be increased compared with the TT group. Similar early onset of parasitaemia was noted in T. vivax infected goats by Adeiza et al. [23] and Osman et al. [31]. The pre-patent period of infection by T. vivax is variable, depending on the immune status of the host, virulence of the parasite isolate and the infective dose [12, 7].

\section{Haematological findings}

In the present study, significant decrease in mean PCV, Hgb concentration, total RBC and WBC counts was observed in all infected groups compared with the non-infected group. In agreement with our findings, Maxie et al. [32] described 

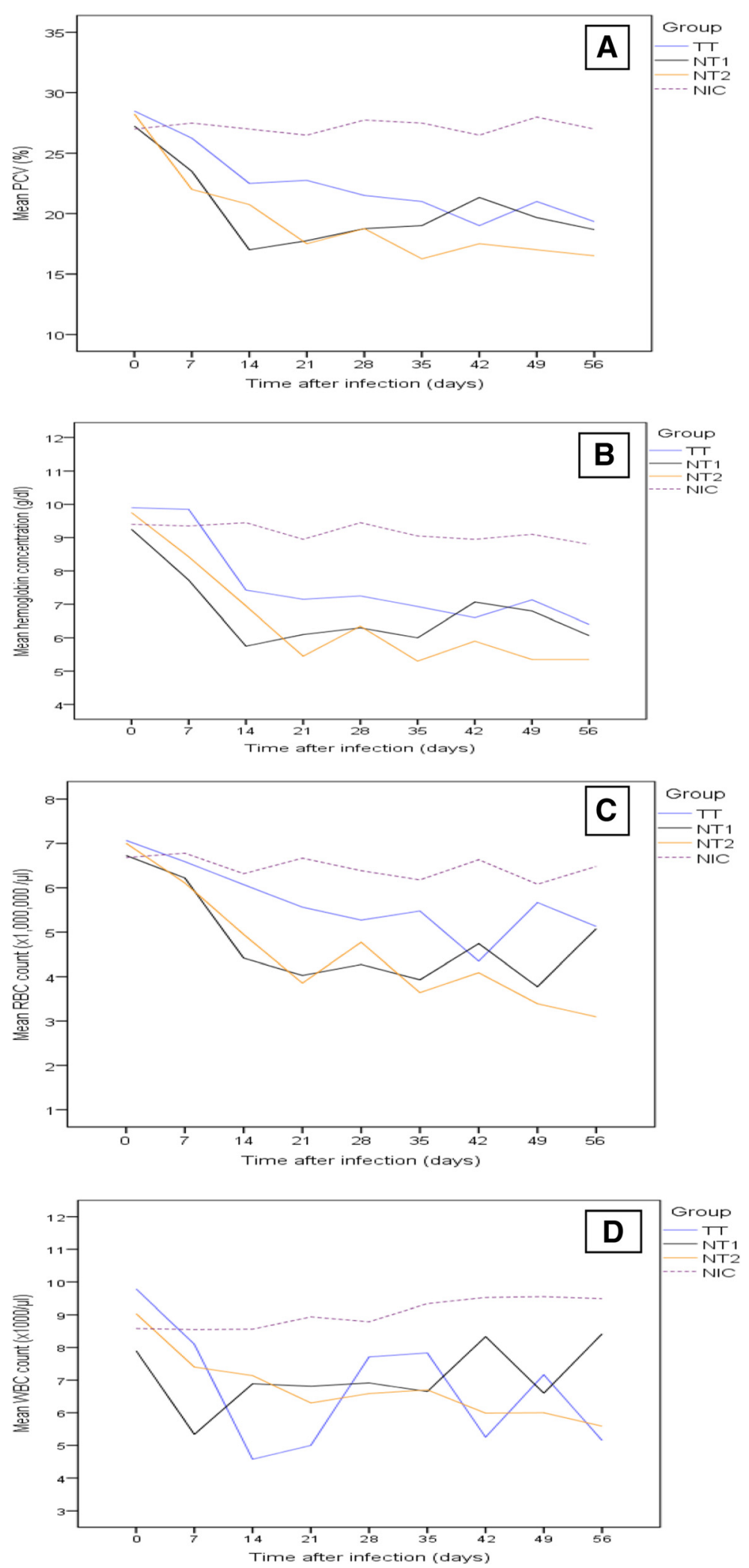

Fig. 2 Mean haematological values in young Zebu cattle experimentally infected with T. vivax isolates from tsetse infested (TT) and non-tsetse infested (NT1 and NT2) areas and non-infected control (NIC) groups during the study period. a Mean PCV values in percent, (b) Mean haemoglobin concentration in $\mathrm{g} / \mathrm{dl}$, (c) Mean total RBC count in $\times 10^{6} \mathrm{cells} / \mu \mathrm{l}$, (d) Mean total WBC count in $\times 10^{3} \mathrm{cells} / \mu \mathrm{l}$ 
pancytopenia, leukopenia, and thrombocytopenia associated with $T$. vivax and $T$. congolense infections of cattle. Similar observations were reported by Osman et al. [31] in goats infected with T. vivax. The decreases in these parameters indicate a state of anaemia in the infected groups and ascertained the presence of anaemia reported by several authors in T. vivax infections in different hosts [33-37]. This anaemia might be due to haemolysis induced by the trypanosomes [38], or haemodilution arising as the fluid content of blood increases. Red cell counts can be reduced as a result of increased erythrophagocytosis, which was found to be an important mechanism leading to anaemia in the pathophysiology of $T$. congolense infection in Zambian goats [39], or of different immunological factors and dyshaemopoiesis in which the bone marrow fails to produce RBC [14, 40]. Haemolysis could also be caused by mechanical injury to erythrocytes by the lashing action of the powerful locomotory flagella and microtubulereinforced bodies of the dense trypanosome population during elevated parasitaemia [41]. Erythrocyte membrane damage has also been postulated to be associated with adhesion of erythrocytes and reticulocytes to the trypanosome surface via sialic acid receptors leading to damage to erythrocyte cell membranes [42]. The significant increase in mean $\mathrm{MCV}$ value and insignificant change of mean $\mathrm{MCH}$ and $\mathrm{MCHC}$ indicate the macrocytic normochromic type of anaemia in infected groups, in agreement with Nadia et al. [43] and Gardiner [5]. Macrocytosis is due to erythrogenesis that takes place after the onset of infection, at which time immature erythrocytes are released into the bloodstream [44].

The reduction in total WBC count observed in this study was similar to that observed in other studies [32, 45, 46]. However, Nadia et al. [43] observed no significant difference in total WBC count in T. vivax infection in Sudanese Nubian goats. The lower counts of WBC, lymphocytes and neutrophils observed in the infected groups may be attributed to the immunosuppressive actions of trypanosome infection [47]. The increase in relative number of monocytes in infected groups may be explained by their role in the destruction of numerous damaged erythrocytes. In the present study, although body weight loss was lower in the NT groups than in the TT group, mainly the NT2 group was more severely affected by anaemia, indicating possibly inter-isolate variation in pathogenicity. Moreover, Shimelis et al. (unpublished data) demonstrated that the immunological response of the TT group was higher than that of the NT groups, which might demand excessive energy, at the expense of more body weight loss. Murray and Dexter [14] showed that the severity of anaemia during trypanosome infection could be related to differences in virulence among trypanosome strains.

\section{Conclusions}

Young Zebu cattle infected with T. vivax isolates developed clinical trypanosomosis, which was associated with reduced feed intake, pyrexia, enlarged superficial lymph nodes, parasitaemia, emaciation, anaemia and leukopenia. T. vivax of a non-tsetse infested isolate (NT2) caused more severe anaemia than the tsetse infested T. vivax isolate, whereas the TT isolate resulted in much higher body weight loss than its NT counterparts. Therefore, the $T$. vivax parasite from non-tsetse infested area can at least be considered as important as that derived from the tsetse infested area.

\begin{abstract}
Abbreviations
MCH: Mean corpuscular haemoglobin; MCHC: Mean corpuscular hemoglobin concentration; MCV: Mean corpuscular volume; NIC: Non-infected control; NT1: Infected group with T. vivax isolate from non-tsetse infested area; NT2: Infected group with another T. vivax isolate from non-tsetse infested area; PCV: Packed cell volume; PID: Post infection day; RBC: Red blood cell; TT: Infected group with T. vivax isolate from tsetse infested area; WBC: White blood cell.
\end{abstract}

\section{Competing interests}

The authors declare that they have no competing interests.

\section{Authors' contributions}

SDN have made substantial contributions to conception and design of the project, acquisition of data, analysis and interpretation of data, drafted the manuscript and final proof reading of the manuscript before submitted to the journal. MB participated in the acquisition of data and laboratory analyses. GT participated in the project design, reviewed and corrected the manuscript on technical and important intellectual contents. GA participated in the design of the study and performed critical review of the manuscript. JDB participated in the design and improvement of the project. BMG participated in the design of the project and critically reviewed the manuscript. All authors read and approved the final manuscript.

\section{Acknowledgment}

Bahir Dar Regional Veterinary Laboratory is acknowledged for the logistic support and enthusiastic encouragement during the field work. The research is funded by Ethio-Belgium VLIR project, GALVmed, and the thematic research project 'Animal Health Improvement' of Addis Ababa University.

\section{Author details}

${ }^{1}$ Department of Pathology and Parasitology, College of Veterinary Medicine and Agriculture of Addis Ababa University, P.O. Box: 34, Debre Zeit, Ethiopia. ${ }^{2}$ Food and Agriculture Organization of the United Nations, Addis Ababa, Ethiopia. ${ }^{3}$ Wellcome Trust Centre for Molecular Parasitology, College of Medicine, Veterinary and Life Sciences, University of Glasgow, 120 University Place, G12 8TA Glasgow, UK. ${ }^{4}$ Department of Biosystems, Faculty of

Bioscience Engineering, Catholic University of Leuven, 30 bus 2456, B-3001 Heverlee, Belgium. ${ }^{5}$ Faculty of Veterinary Medicine, University of Gondar, P.O. Box: 196, Gondar, Ethiopia.

Received: 16 October 2014 Accepted: 14 May 2015

Published online: 19 May 2015

\section{References}

1. Igbokwe 1O. Mechanisms of cellular injury in African trypanosomiasis. Vet Bull. 1994;64:611-20.

2. Radostitis DM, Gay CC, Hinchelift KW, Constable PC. Veterinary medicine: a textbook of the diseases of cattle, sheep, goats, pigs and horses. 10th ed. London: W.B. Saunders Co. Ltd.; 2006. p. 1531-40.

3. Swallow BM. Impacts of trypanosomiasis on African agriculture. Nairobi, Kenya: ILRI (International Livestock Research Institute); 2000. p. 1-46.

4. Desquesnes M, Dia ML. Trypanosoma vivax: mechanical transmission in cattle by one of the most common African tabanids, Atylotus agrestis. Exp Parasitol. 2003;103:35-43 
5. Gardiner PR. Recent studies of the biology of Trypanosoma vivax. Adv Parasitol. 1989;28:229-317.

6. Jones TW, Dávila AM. Trypanosoma vivax-out of Africa. Trends Parasitol. 2001;17:99-101.

7. Osorio AL, Madruga CR, Desquesnes M, Soares CO, Ribeiro LR, Costa SC. Trypanosoma (Duttonella) vivax: its biology, epidemiology, pathogenesis, and introduction in the New World-a review. Mem Inst Oswaldo Cruz. 2008;103:1-13.

8. Abebe G. Trypanosomosis in Ethiopia: a review. Ethiop J Biol Sci. 2005;4:75-121.

9. Dagnachew S, Sangwan AK, Abebe G. Epidemiology of bovine trypanosomosis in the Abay (Blue Nile) basin areas of Northwest Ethiopia. Revue d'élevage et demedecine vétérinaire des pays tropicaux. 2005:58:151-7.

10. Cherenet T, Sani RA, Speybroeck N, Panandam JM, Nadzr S, Van den Bossche P. A comparative longitudinal study of bovine trypanosomiasis in tsetse-free and tsetse-infested zones of the Amhara Region, Northwest Ethiopia. Vet Parasitol. 2006;140:251-8.

11. Sinshaw A, Abebe G, Desquesnes M, Yoin W. Biting flies and Trypanosoma vivax infection in three highland districts bordering Lake Tana, Ethiopia. Vet Parasitol. 2006;142:35-46

12. Taylor K, Authié EML. Pathogenesis of Animal Trypanosomiasis. In: Maudlin I, Holmes PH, Miles MA, editors. The Trypanosomiases. Wallingford: CABI Publishing; 2004. p. 331-53.

13. Coles EH. Veterinary clinical pathology. 4th ed. Philadelphia, USA: W.B. Saunders Co.; 1986. p. 1-486.

14. Murray M, Dexter TM. Anaemia in bovine African trypanosomiasis (A review). Acta Trop. 1988:45:389-432.

15. Silva RAMS, Ramirez L, Souza SS, Ortiz AG, Pereira SR, Davila AMR. Haematology of natural bovine trypanosomosis in the Brazilian Pantanal and Bolivian wetlands. Vet Parasitol. 1999;85:87-93.

16. Mwongela GN, Kovatch RM, Frazil MA. Acute Trypanosoma vivax infection in dairy cattle in Coastal Province of Kenya. Trop Anim Health Prod. 1981;13:63-9.

17. Council for International Organizations of Medical Sciences (CIOMS). International Guiding Principles for Biomedical Research Involving Animals. 1985.

18. Kilkenny C, Browne WJ, Cuthill IC, Emerson M, Altman DG. Improving bioscience research reporting: the ARRIVE guidelines for reporting animal research. PLoS Biol. 2010;8, e1000412.

19. Masiga DK, Smyth AJ, Hayes P, Bromidge TJ, Gibson WC. Sensitive detection of trypanosomes in tsetse flies by DNA amplification. Int J Parasitol. 1992;22:909-18

20. Duffy CW, Morrison $\sqcup$, Black A, Pinchbeck GL, Christley RM, Schoenefeld A, et al. Trypanosoma vivax displays a clonal population structure. Int J Parasitol. 2009;39:1475-83.

21. Herbert WJ, Lumsden WHR. Trypanosoma brucei: a rapid "matching" method for estimating the host's parasitaemia. Exp Parasitol. 1976;40:427-31.

22. Murray M, Murray PK, Mcintyre WIM. An improved technique for the diagnosis of African trypanosomiasis. Trans R Soc Trop Med Hyg. 1977;71:325-6.

23. Adeiza AA, Maikai VA, Lawal Al. Comparative haematological changes in experimentally infected Savannah brown goats with Trypanosoma brucei and Trypanosoma vivax. Afri J Biotech. 2008;7:2295-8.

24. Rowlands GJ, Mulatu W, Authié E, d'leteren GDM, Leak SGA, Nagda SM. Effects of trypanosomiasis on growth and mortality of young East African Zebu cattle exposed to drug-resistant trypanosomes. Prev Vet Med. 1994:21:87-101.

25. Osaerio S, Goossens B, Jeffcoate I, Holmes P. Effects of Trypanosoma congolense and nutritional supplements in Djallonké ewes on live weight during pregnancy, postpartum weight, haematology parameters and lamb performance. Res Vet Sci. 1998;65:65-9.

26. Turner CMR, Aslam N, Dye C. Replication, differentiation, growth and the virulence of Trypanosoma brucei infections. Parasitol. 1995;11:289-300.

27. Spence PJ, Jarra W, Lévy P, Reid AJ, Chappell L, Brugat T, et al. Malaria's severity reset by mosquito. Vector transmission regulates immune control of Plasmodium virulence. Nature. 2013:498:228-31.

28. Shapiro SZ, Naessens J, Liesegang B, Moloo SK, Magondu J. Analysis by flow cytometry of DNA synthesis during the life cycle of African trypanosomes. Acta Trop. 1984;41:313-23.
29. MacGregor P, Savill NJ, Hall D, Matthews KR. Transmission stages dominate trypanosome within-host dynamics during chronic infections. Cell Host Microbe. 2011;9:310-8.

30. Dagnachew S, Terefe G, Abebe G, Barry DJ, Goddeeris BM. Comparative biochemical changes in young Zebu cattle experimentally infected with Trypanosoma vivax from tsetse infested and non-tsetse infested areas of northwest Ethiopia. Vet Parasitol. 2014;205:451-9.

31. Osman NM, Kaila GJ, Eltahir HA, Abdel-Rahman AH. Susceptibility of Sudanese Nubian goats, Nilotic dwarf goats and Garag ewes to experimental infection with a mechanically transmitted Trypanosoma vivax stock. Pakistan J Biol Sci. 2008;11:472-5.

32. Maxie MG, Losos GJ, Tabel H. Experimental bovine trypanosomiasis (Trypanosoma vivax and T. congolense). I. Symptomatology and clinical pathology. Tropenmed Parasitol. 1979;30:274-82.

33. Van den Ingh TS, Zwart D, Van Miert AS, Schotman AJH. Clinicopathological and morphological observations in Trypanosoma vivax infection in cattle. Vet Parasitol. 1976;2:237-50.

34. Igbowke IO, Anosa VO. Response to anaemia in experimental Trypanosoma vivax infection of sheep. J Comp Pathol. 1989;100:111-8.

35. Sekoni VO, Saror DI, Njoku CO, Kumi-Diaka J, Opaluwa Gl. Comparative haematological changes following Trypanosoma vivax and T. congolense infections in Zebu bulls. Vet Parasitol. 1990;35:11-9.

36. Okech $G$, Watson ED, Lukins AG, Makawiti DW. The effect of experimental infection of Boran cattle in early and mid-pregnancy with Trypanosoma vivax. Br Vet J. 1996;152:441-51.

37. Sharma DK, Chauhanb PPS, Saxenac VK, Agrawal RD. Haematological changes in experimental trypanosomiasis in Barbari goats. Small Rum Res. 2000;38:145-9.

38. Soulsby EJL. Helminthes, arthropods and protozoa of domesticated animals. 7th ed. London: Bailliere Tindall and Cassell; 1982. p. 809.

39. Witola WH, Lovelace CE. Demonstration of erythrophagocytosis in Trypanosoma congolense infected goats. Vet Parasitol. 2001;96:115-26.

40. Mbaya A, Kumshe H, Nwosu C. The mechanisms of anaemia in trypanosomosis: a review. In: Silverberg D, editor. Anaemia. Shanghai: In Tech; 2012. p. 269-82

41. Vickerman K, Tetley L. Biology and ultra structure of trypanosomes in relation to pathogenesis. In: Pathogenicity of trypanosomes. Proceedings of a workshop, November 20-23, Nairobi, Kenya. 1978. p. 23-31.

42. Anosa VO, Kaneko JJ. Pathogenesis of Trypanosoma brucei infection in dee mice (Peromyscus maniculatus), Light and electron microscopic studies on erythrocyte pathologic changes and phagocytosis. Amer J Vet Res. 1983:44:645-51.

43. Nadia MO, Mohamed F, Ahmed HA. Haematological profile and parasitological diagnosis of Trypanosoma Vivax infection in Sudanese Nubian goats. Univ Khartoum J Vet Med Anim Prod. 2012;3:28-45.

44. Anosa $V$, Isoun T. Haematological studies on Trypanosoma vivax infection of goats and intact and splenectomized sheep. J Comp Pathol. 1980;90:155-68.

45. Bengaly Z, Sidibe I, Ganaba R, Desquesnes M, Boly H, Sawadogo L. Pathogenicity of three genetically distinct types of Trypanosoma congolense in cattle: clinical observations and haematological changes. Vet Parasitol. 2002:108:1-19.

46. Allam L, Ogwu D, Agbede IS, Sackey KB. Haematological and serum biochemical changes in gilts experimentally infected with Trypanosoma brucei. Veterinari Arhiv. 2011;81:597-609.

47. Ekanem JT, Yusuf OK. Some biochemical and haematological effects of black seed (Nigella sativa) oil on T. brucei-infected rats. Afr J Biomed Res. 2008;11:79-85. 